\title{
Reacting to the COVID-19 pandemic through digital connectivity with customers: the Italian experience
}

\section{Marco Bettiol $^{1} \cdot$ Mauro Capestro $^{1}$ (D) Eleonora Di Maria ${ }^{1} \cdot$ Stefano Micelli $^{2}$}

Received: 18 January 2021 / Accepted: 26 May 2021 / Published online: 6 June 2021

(c) The Author(s) 2021

\begin{abstract}
The COVID-19 has deeply impacted the firm's competitiveness because of the restrictions that limited the relationships with existing and new customers. The pandemic has pushed firms to rely on digital technologies to redefine business processes as well as customer relationships and marketing strategies. The digital technological portfolio firms may rely on to face the COVID-19 related challenges spanning from the established web-based technologies to the more recent Industry 4.0 tools related to the fourth industrial revolution. In this regard, the paper aims at exploring which digital technologies allowed firms to positively react to the pandemic to overcome their constraints in managing the market relationships. Based on an original qualitative analysis on 26 Italian SMEs carried out during the first Italian lockdown in 2020 , the paper identifies three strategies in the use of digital technologies to support customer relationship management and market expansion. It emerges specifically the strategic importance of web-based technologies (videoconferencing, CRM and e-commerce) to support firm competition and performance through customer interactions and digital experience, advancing the literature on firms' reaction strategies during turbulent and crisis times.
\end{abstract}

Keywords COVID-19 · Digital technologies · Web-based technologies · Industry $4.0 \cdot$ Customer relationships

\section{Introduction}

The COVID-19 pandemic had a dramatic impact on several countries across the world. National governments have imposed widespread restrictions to prevent the development of the pandemic (Verma \& Gustafsson, 2020). The new competitive

Mauro Capestro

mauro.capestro@unipd.it

1 Department of Economics and Management, University of Padova, Padova, Italy

2 Department of Management, Ca' Foscari University, Venice, Italy 
scenario induced by the COVID-19 crisis raised many issues on how business activities should be re-organized due to the difficulties of physical interactions with employees, distributors, suppliers and customers (Sheth, 2020). The pandemic has particularly affected the marketing processes because of the relevant issues emerged in managing physical sales channels and interactions with customers, both in the Business-to-Consumer (B2C) and in the Business-to-Business (B2B) markets (Kang et al., 2020; Wang et al., 2020).

Recent research about the appropriate actions and strategies that could help firms to overcome the crisis has highlighted the key role of digital technologies that may ensure connections and, thus, help business activities to run smoothly (Yin et al., 2020). This could be true especially with the emergence of strong limitations on physical interactions as during the COVID-19 pandemic (Papadopoulos et al., 2020). In such a scenario, the online channel becomes the most important environment for customers to get in contact with the firm and carry out purchasing activities (Hoekstra \& Leeflang, 2020). Firms should push technological investments to provide a digital experience, manage product configuration and/or support sales directly (Siggelkow \& Terwiesch, 2019). In this specific environmental condition, different digital technologies may help firms to define innovative strategies to approach the market as well as to define new business models (Chesbrough, 2020), enabling firms to develop new business opportunities (Nenonen \& Storbacka, 2020).

Past marketing research has highlighted the potential of information technologies (IT) and specifically of web-based technologies in designing effective customer relationship management both in terms of one-to-one marketing (Peppers et al., 1999) and community-based framework (Armstrong \& Hagel, 1996; Kozinets, 1999). According to scholars, the revolution of the web completely transformed marketing strategies (Sharma \& Sheth, 2004) as enabled firms to benefit from digital technologies in terms of exchanging information with customers and managing complex relationships to strengthen product innovation, brand management, and more broadly value creation.

More recently, studies on Industry 4.0 technologies have pushed forward this debate by emphasizing the predictive potential of data analytics for marketing (Davenport et al., 2020). The new wave of technologies that firms may use in the production domain, such as 3D printing, connected with data-processing technologies, such as big data, artificial intelligence (AI) and Internet of Things (IoT), all included under the umbrella concept of Industry 4.0 (Frank et al., 2019b), have opened new scenarios for value creation (Sauter et al., 2015) linked to the firm's possibility to increase data gathering and the analysis of customers' needs and behaviors, through constant active interactions with customers as well as passive data collection flows (i.e., through smart products) (Iansiti \& Lakhani, 2014; Porter \& Heppelmann, 2014). Based on such innovative technologies, the firm may redesign their offerings in terms of new products and servitization (Frank et al., 2019a) within a deeper customer relationship management connected to a marketing 4.0 scenario (Kotler et al., 2017).

Despite the attention on the key role of digital transformation in facing the COVID-19 crisis and better positioning after the COVID-19 pandemic (Rapaccini et al., 2020), there is very limited evidence on how the different digital technologies 
(web-based vs Industry 4.0) supported firms to overcome the challenges emerged from the COVID-19 pandemic. In so doing, the paper aims at exploring the relationship between digital technologies and the firm's reaction to pandemic challenges, focusing on the context of customer relationship management. More specifically, the goal is to investigate to what extent the mentioned digital technologies have positively supported the firm's reaction to the pandemic constraints in their market relationships. Based on an original empirical analysis of 26 Italian firms interviewed during the first Italian lockdown in 2020, the paper highlights the key role of webbased technologies to immediately interact with customers and try to overcome the pandemic challenges, advancing the literature on the firms' reaction strategies to the COVID-19 crisis and, more broadly, on firm's strategies in turbulent and crisis times. In particular, the paper shows that web-based technologies may be able, in the short time, to put in place new marketing strategies to overcome the crisis.

The paper is structured as follows: in section two we review the literature on customer relationships and digital technologies, taking into consideration also the crisis period; in sections three and four, the methodology and results are presented; in section five we discuss the results and then a final conclusive section is devoted to propose theoretical and managerial implications as well as limitations of the study and suggestions for future research.

\section{Theoretical background}

\subsection{Customer relationships and digitalization}

The rise of Internet and of the Web has deeply transformed the use of IT with respect to the relationships between the firm and the customers. According to literature (Peppers et al., 1999; Wells et al., 1999), through its own website, the firm is able to create a one-to-one relationship with customers, by enhancing customized communication and using data collection for targeted value propositions. The Web becomes a new bidirectional communication channel where the firm can define multiple contents and where also customers can contribute directly (Sharma \& Sheth, 2004). At the same time, through Internet it becomes possible to couple the extended market reach and richness in customer relationships (Evans \& Wurster, 2000), opening mass customization opportunities.

The revolution of the Web has also enhanced knowledge management processes related to the customer, empowering customers and reducing their dependence on the firm (Micelli, 2017). Due to the virtual environment and the advent of online communities of consumption (Kozinets, 2002), customers become active players in the process of new product development (Nambisan \& Nambisan, 2008) as well as in supporting other customers based on their purchasing experience or specialized knowledge (Sawhney et al., 2005). Online communities are essential for supporting business innovation through open knowledge sharing (Marchi et al., 2011; Schau et al., 2009). According to the digitalization of customer relationship management, marketing processes are enhanced, and marketing strategies can be redesigned to 
leverage on the proactive role of customers during the product lifecycle and to identifying new value generation opportunities (Siggelkow \& Terwiesch, 2019).

The development of e-commerce has in particular further reinforced this intimacy and connection with customers. On the one hand, the product sale and its communication process are tightly connected through the development and management of digital content (Chaffey et al., 2019). Brand management becomes a shared process where customers are directly involved and can participate in nurturing brand meaning through their communication (Kotler et al., 2017). Moreover, customers can provide feedback and the firm can rely on the analysis of data based on past purchasing behavior for recommendation and product development. On the other hand, the e-commerce scenario impacts on the firm's channels management, where the customer has multiple online entry points to collect information, compare products and to complete her purchasing activities.

The CRM solutions represent an Internet technology that enables the integration among the different processes connected to the customer and the related information (Sin et al., 2005). CRM allows gathering and managing customer information effectively to better understand their needs and strategically support customer lifecycle management in relation with e-commerce as well as social media (Acker et al., 2011; Kotler et al., 2017). This technology is considered essential to build effective relationships with customers for both B2B and B2C firms as allows them "to formulate more appropriate marketing strategies and to execute specific marketing actions more efficiently and quickly by offering superior first-line support and the access of integrated access customer data" (Chang et al., 2010, p. 850). From this perspective, effective customer relationship management (CRM) becomes a strategic imperative for each firm that could be closer to their customers and, thus, they should put more effort in finding new ways to create value from the information they receive, to improve the customer journey as well as her loyalty (Park \& Kim, 2003).

This scenario has been recently transformed due to the increased attention for new technologies related to the concept of Industry 4.0. This wide set of technologies has promised to radically transform manufacturing activities (Alcácer \& CruzMachado, 2019), but also marketing processes. Through advanced and connected automation or additive manufacturing (i.e., 3D printing) firms may increase opportunities for product customization in a mass customization paradigm, up to tailored solutions for customers (Di Roma, 2017; Liao et al., 2017). More specifically, the Industry 4.0 technologies are connected to data management and predictive analytics (Tao et al., 2018) that represent one of the most relevant areas for marketing (Erevelles et al., 2016). In the fourth industrial revolution, firms can invest to transform their products into smart products (IoT) to create a constant data flow enabling further product and service development as well as new sources of value creation (Iansiti \& Lakhani, 2014; Porter \& Heppelmann, 2014). Specifically, data-processing technologies may represent interesting opportunity marketing-wise. The possibility to analyze customer behavior and to exploit their feedback for new offering is made possible by big data analytics and AI solutions (Davenport et al., 2020; De Luca et al., 2020). There are multiple marketing applications to support the relationships with customers in the AI domain (Grandinetti, 2020; Mandelli, 2018). Firms can exploit big data analytics to provide better customer services, by anticipating 
customers' needs and behaviors, also relying on a larger scale of data to provide a more refined and advanced market analysis. Another important related area of AIsupported marketing refers to the customization of online communication strategies designed to optimize the customer's experience (Brill et al., 2019).

\subsection{Managing customers in the pandemic scenario: investigating the role of technologies}

The COVID-19 pandemic, and the following crisis emerged, has radically put attention on how firms effectively reach customers, specifically when physical interactions and mobility have been limited by lockdown. Digital technologies have been highlighted as important tools firms can use to overcome the limitations of the pandemic (Soto-Acosta, 2020) as they may enable business processes and services to ensure continuity and interaction while data are gathered to define new strategies (Papadopoulos et al., 2020).

The pandemic has impacted on customer relationship management in multiple directions, both in the B2C and B2B markets. First, firms have experienced limits in interacting with customers during the sales process due to the lockdown, especially when customized products have to be developed. Without the possibility to interact face-to-face firms may have seen a reduced possibility to develop products that requires rich interaction with customers (Wu et al., 2016). Second, lockdown has interrupted retailing activities rooted on physical sales through brick-and-mortar stores, with negative consequences specifically for firms with no or limited ecommerce solutions already in place. Third, the limitation in international mobility has also challenged firms operating in international markets, in terms of information provision to potential customers related to their offerings or the possibility to reach existing customers (Zafari et al., 2020). This is particularly relevant in the B2B context, where often buyers and suppliers meet in person and the communication on products and purchasing process are defined interactively (Österle et al., 2018). Indeed, the COVID-19 pandemic has negatively impacted not only the B2C market (Chesbrough, 2020), but also the B2B context (Cankurtaran \& Beverland, 2020) where firms had to react to limitations in sales activities (Hartmann \& Lussier, 2020) by redesigning the organizational resources, also enhancing the use of technological infrastructures to manage the progressive blurring between channels. From this point of view, several constraints on national and international mobility have blocked or reduced the possibility of organizing business fairs that were one of the most important marketing initiatives in the B2B context (Kang et al., 2020).

On the one hand, recent reports on COVID-19 have stressed the rise in the use of Internet and social media (Donthu \& Gustafsson, 2020). The customer's behavior has changed during the lockdown and a massive use of the web and social media have become the channels to manage product information gathering and purchasing activities. Especially digital products or priority goods, such as food, have experienced an increased in sales, while many others have suffered. The crisis has pushed firms to overcome the challenges in reaching and managing markets by further 
considering digitalization within the web-based environment (Kim, 2020; Papadopoulos et al., 2020).

On the other hand, the fourth industrial revolution centered on Industry 4.0 technologies opens new opportunities for enhancing customer relationship management to overcome the challenges mentioned above. Data-processing technologies that rely on data to provide information-driven input for decision making (Culot et al., 2020) can support firms in developing innovative products/services, to approach existing markets or enter in new ones, as well as in defining new business models and supporting the decision-making process, leveraging on data about customers and markets (Frank et al., 2019a).

The COVID-19 crisis has been particularly rapid in its spread across industries, markets, and countries, requiring firms of adopting solutions very quickly to not suffer from the negative consequences of lockdown (Eggers, 2020). This scenario opens new issues on the technologies adopted (He et al., 2021) and on the marketing processes (Kang et al., 2020) supported by such digitalization during the pandemic, specifically as far as customer relationship management is concerned. Research on digital transformation highlights that technologies have different characteristics in terms of potentiality for marketing purposes and in terms of time required for implementation (Robert et al., 2020). Previous studies show that both the adoption rate and the implementation process of the different digital technologies (the more mature web-based technologies and the more recent Industry 4.0 technologies) is uneven among firms of different sizes and industries (Bettiol et al., 2020a). It should not be taken for granted that technologies related to the web-based revolution and those of the fourth industrial revolution have been adopted and exploited by firms in the same manner (Ghobakhloo \& Fathi, 2020).

Further knowledge is, therefore, required to better disentangle the role of the different digital technologies in supporting firms during the COVID-19 pandemic, specifically in implementing customer-wise marketing activities. This study aims at answering to the following research questions: Which are the digital technologies that firms mainly used during the COVID-19 pandemic? How did firms use digital technologies to manage customer relationships and react to the COVID-19 challenges?

\section{Methodology}

The study draws on in-depth interviews carried out on Italian manufacturing smalland medium-sized firms ${ }^{1}$ (SMEs) collected during the COVID-19 pandemic (May and June 2020) to explore how firms responded to the COVID-19 challenges with a main attention on the use of digital technologies and the interaction with customers. Due to the extraordinary event representing our empirical context (the pandemic), following recent literature, we chose an opportunistic method (Burd, 2019) for

\footnotetext{
1 We focused on SMEs because they represent the $99.7 \%$ of the Italian manufacturing companies as it is evident from https://www.istat.it/it/files/2019/12/C14.pdf
} 
case study selection. We engaged a sample of Italian SMEs interviewed through an online survey between September 2019 and January 2020, thus immediately before the beginning of the pandemic. The online survey, aimed at assessing the firm's technological (IT and Industry 4.0 technologies) investment strategy, has been carried out on a stratified sample of Italian SMEs operating in some of the most important Italian manufacturing (such as food, automotive, chemical and pharmaceuticals, mechanics, home systems, and fashion) and services industries (such as logistics and transport and IT) and allowed to gather 366 questionnaires. Findings of the first quantitative study allowed us to set up and deploy the qualitative study related to the COVID-19. The choice to consider the sample of firms involved in the online survey for the interviews carried out during the COVID-19 pandemic was driven by the opportunity to have data about the adoption of different technologies that may favor the exploration about how firms have adapted their strategies in terms of use to face the COVID-19 challenges, especially as a consequence of the changes occurred with customers.

During the first Italian lockdown (April 2020), we engaged by emailing all the firms that participated to the previous online survey (366 firms), for a qualitative study based on in-depth interviews, and we were able to collect 26 useful interviews with firms operating in different industries and markets (B2B and B2C) (Table 1). We interviewed entrepreneurs, CEOs, and/or managers of the firms through a set of open-ended questions that followed an interview guideline in order to keep the conversation structured and on point. Specifically, after a brief description of the firm's activity, the questions aimed to assess more in depth: (1) the impacts of COVID19 on business processes and performance as well as on customer interactions; (2) the role of digital technologies in facing the COVID-19 pandemic; (3) the related strategies in terms of process and product innovation (with a focus on customer relationships). For each one of the three key-points investigated, we asked to the respondents to describe the current situation (also in relation to the past) as well as to provide their perception about the future.

Each interview lasted from 60 to $90 \mathrm{~min}$ and benefited from documentation and results from the prior study. All interviews were taped and transcribed verbatim to increase the findings' reliability (Yin, 2004). To reach our research purposes, from the interviews collected, we proceed through a multiple-process analysis based on: (1) a word cloud analysis to extract the main words emerged from the interview with the firms and summarized through the word cloud; (2) a cross-case analysis based on frequency and content analysis to assess the firm's technological endowment, its use and main strategic purposes during the pandemic and outline preliminary results; (3) a selected case study analysis (Siggelkow, 2007) to highlight how firms responded to the COVID-19 pandemic based on the results of phase 2 .

The interviews collected were processed with the MAXQDA software (released by VERBI GmbH). Starting from the punctual transcription of the interviews conducted, we proceeded to clean the same interviews and relative files (avoiding the redundant question-answer effect). After that, the text of all interviews were loaded into MAXQDA to perform a first textual cleaning (i.e., a list of words to be excluded from the textual analysis such as articles, prepositions and some other words closely related to the pandemic crisis and not pertaining 


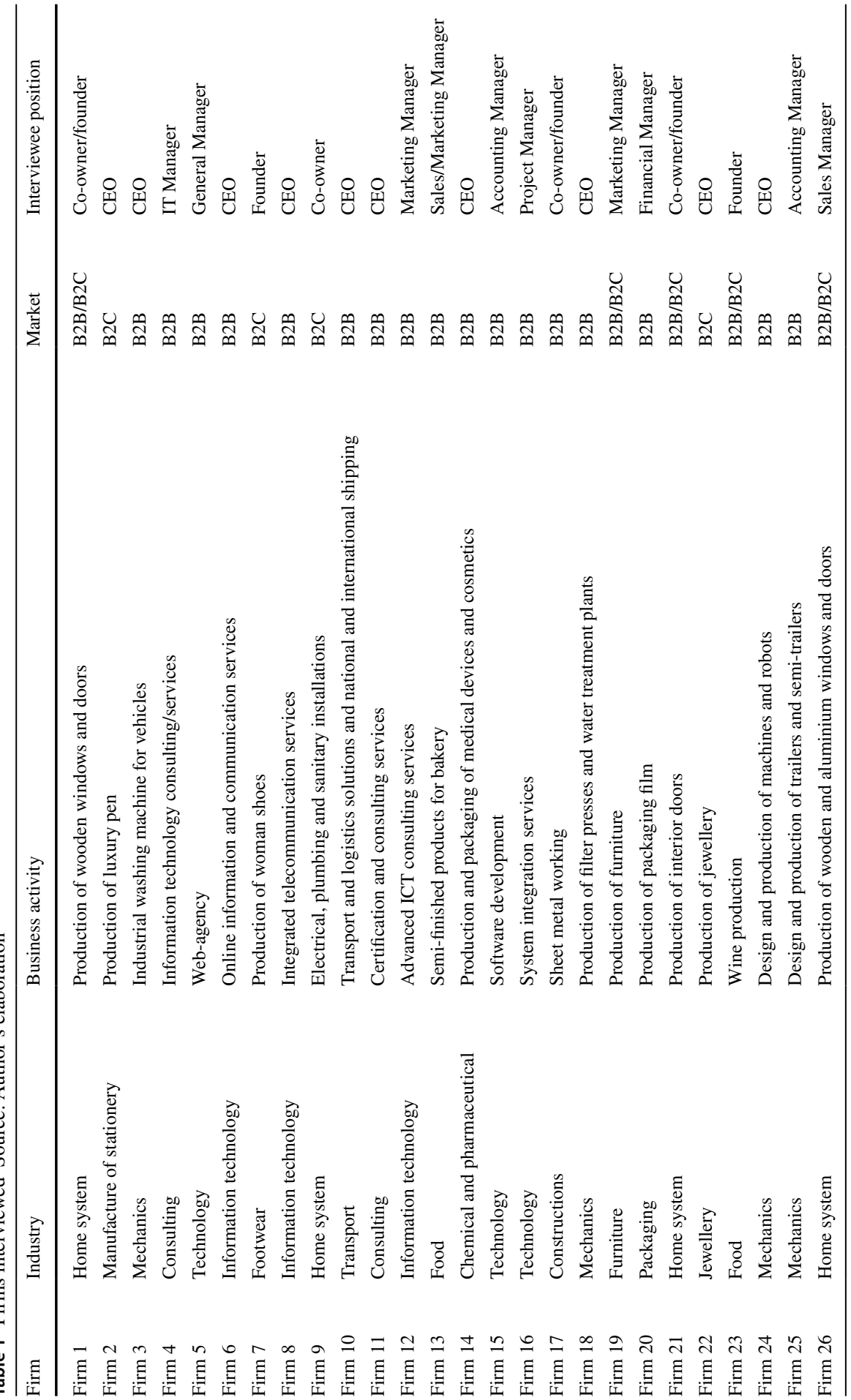


to the research context). Then, the further textual cleaning occurred according to the following criteria: (1) the same word present in both singular and plural was counted as a single word; (2) words that had the same meaning (therefore synonyms) were considered as a single word in the final count; (3) words that take on a different meaning if used in conjunction with other words (typical example, the unemployment benefit fund and smart working) were searched individually in the text of the interviews to understand if they went alone or accompanied by other words. Finally, for the word cloud analysis, after the cleaning process, from the total number of words that emerged, only those with a minimum frequency of 10 were included in the word cloud. In total, 69 words, whose frequency ranges from 10 to 192 formed the cloud. Regarding to the visualization of the words, the following visualization modes made available by the MAXQDA software were chosen: (1) frequency: words more frequent are larger; (2) scale (affects the size differences between common and rare words): larger for more frequent, i.e. the font size is proportional to the square of the word frequency; (3) word-order: random.

In the second step of the analysis, through the frequency analysis, we aimed at assessing the technological endowment of the firms interviewed, taking into consideration information and web-based technologies, such as website, social media and e-commerce (Abed et al., 2015), as well as the enterprise-business management technologies, such as Enterprise Resource Planning (ERP), CRM and Supply Chain Management (SCM) (Hendricks et al. 2007), and the main enabling Industry 4.0 technologies (Frank et al., 2019b). In addition, in this step we proceed to evaluate how the firms interviewed used technologies to face the crisis emerged from the COVID-19 pandemic during the Italian lockdown.

Finally, in the third step of the analysis, taking into consideration both the research purposes and the results emerged from the previous step of analysis, we selected and focused on the three most important case studies (Siggelkow, 2007) to better present how and which main technologies were used to interact with customers and face the market turbulence created by the pandemic in the short-time.

\section{Results}

\subsection{Firm's priorities during the COVID-19 pandemic: a word cloud analysis}

The first step of analysis regards the assessment of the key words of the interviews collected to highlight what are the relevant factors related to the research purposes. The word cloud (Fig. 1) is a visual representation of word frequency (Zikmund, 2013) which provides a first quick look for formative purposes (Depaolo and Wilkinson, 2014).

The main result emerged from this first analysis is the strategic role of customers for firms during the pandemic. Indeed, this perspective has been outlined by many firms such as the CEO of Firm 2, who stressed the relevance to take care of customers during the pandemic to assure long-term relationships: 


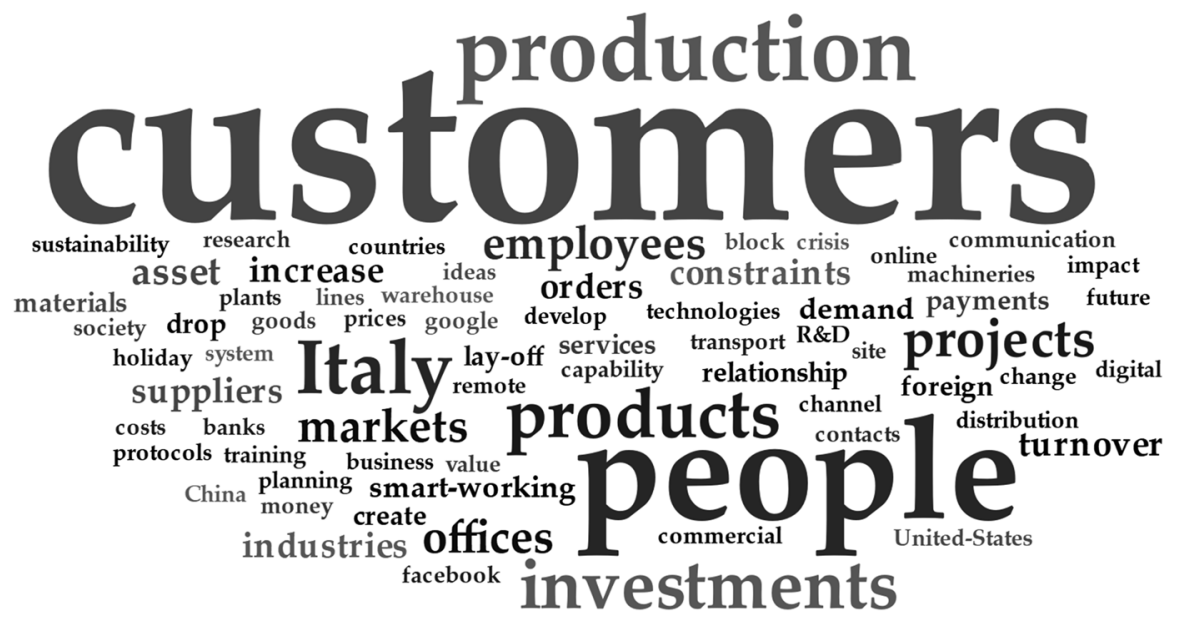

Fig. 1 Key words mentioned by interviewed firms Source: Author's elaboration

"We delivered a bar of chocolate with the shape of a nib to all our customers, so it was made as a nib to offer them a start, a little sweeter and a little less bitter than all problems that surely everyone will encounter in the reopening, in the reorganization, of their store, etc. There is the thought of continuing to say and tell that you are there, that you are close and talk to your customers in a different way, and I think this will be a new way to express proximity, the proximity of our brand, the proximity of the product, the proximity of the people, ok technology but also humanity".

In addition to the key role of customers, the word cloud reveals other key terms, mainly related to product and production, which need specific consideration due to the restrictions imposed by the pandemic situation. Other key concepts are related to the markets and to Italy (in terms of upstream and downstream strategies) and the investment in new technologies to digitalize the business process with the aim to favor the relationship with customers. These preliminary results allow us to take knowledge about the main factor (customers) on which should be focused the firm strategy to face the COVID-19 pandemic, better explored in the next steps.

\subsection{Use of digital technologies during the COVID-19 pandemic}

In the second step of the analysis, we firstly assessed the firm's technological endowment through the data collected by the online survey, and then we focused on assessing, through the content analysis of interviews, the use of digital technologies during the COVID-19 pandemic. As shown by the frequencies reported in Table 2, there is an uneven distribution of technologies adopted, being website, social media, ERP and CRM the most adopted ones (Table 2).

The most adopted technologies are web-based technologies such as website and social media that firms mainly use to communicate with the external environment, 
Table 2 Technology adoption rate. Source: Author's elaboration

\begin{tabular}{llc}
\hline Technology & Frequency & Percentage (\%) \\
\hline Website & 26 & 100.0 \\
Social media & 18 & 69.2 \\
ERP & 16 & 61.5 \\
CRM & 12 & 46.2 \\
Cloud & 8 & 30.8 \\
E-commerce & 4 & 15.4 \\
SCM & 4 & 15.4 \\
Autonomous robots & 4 & 15.4 \\
Value chain integration systems & 3 & 11.5 \\
Cybersecurity & 3 & 11.5 \\
Artificial intelligence & 3 & 11.5 \\
IoT & 3 & 11.5 \\
3D printing & 2 & 7.7 \\
Big data & 2 & 7.7 \\
Blockchain & 1 & 3.8 \\
\hline
\end{tabular}

and ERP and CRM, essential to manage effectively the business processes and relationships with customers. More limited adoption refers to cloud, e-commerce, SCM and autonomous robotics. E-commerce is a strategic technology for SMEs to have access to global markets and to gain competitive advantages (Drew, 2003). SCM and robotics are key technologies production processes (Hofmann et al., 2019). Cloud is a cross-function technology that firms use to storage data (Marston et al., 2011). Consistently with other studies, less adopted technologies can be included into the Industry 4.0 framework, which usually require more complex implementation processes (Frank et al., 2019b).

As far as the use of digital technologies during the COVID-19 is concerned, from the content analysis performed, some interesting findings emerged. In particular, with the interviews, we aimed at assessing if firms have increased the use of digital technologies, or modified the strategic approach to the use of digital technologies to sustain customer relationships and business. Table 3 summarizes the results of the analysis, highlighting the marketing-related processes operated through the use of digital technologies during the COVID-19 pandemic. Specifically, Table 3 points out which digital technologies the firms interviewed used to interact with customers, manage relationships with them, and manage and/or support the sales activities during the COVID-19 pandemic.

From this preliminary overview, a cross-case analysis has been conducted to outline any common paths in the use of digital technologies and overcome the challenges of the pandemic. Table 4 presents a summary depicting the relationships between the most used technologies during the lockdown, the specific use within the relationship with the customer and the broader strategic purpose achieved.

From the content analysis of the interviews collected, it emerges that firms modified their use of digital technology in terms of both breadth (number of technologies used, i.e., CRM in addition to ERP) and depth (the intensity of use of 


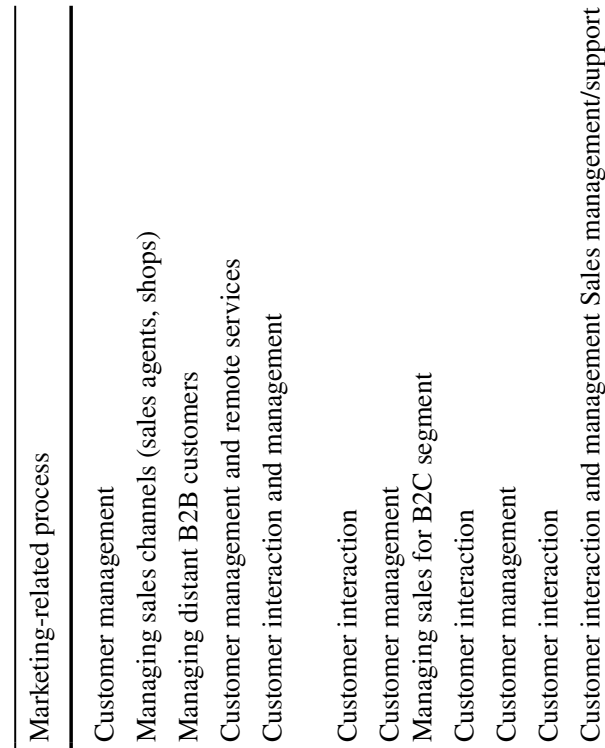

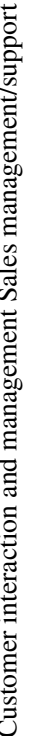

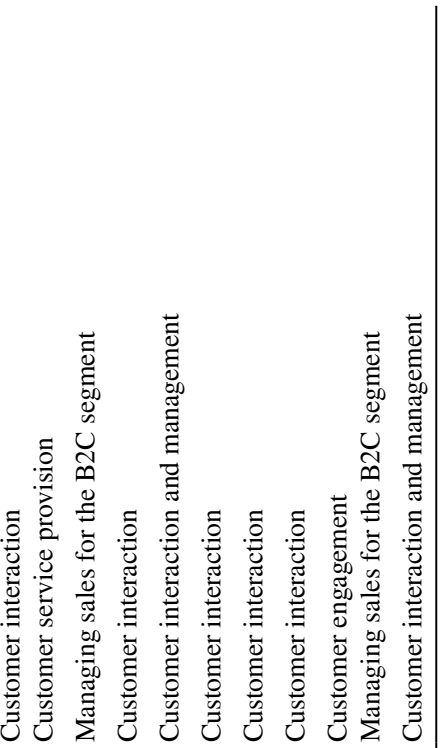

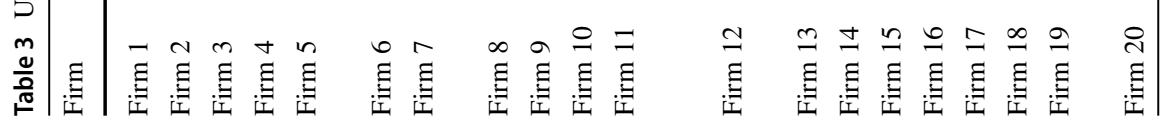




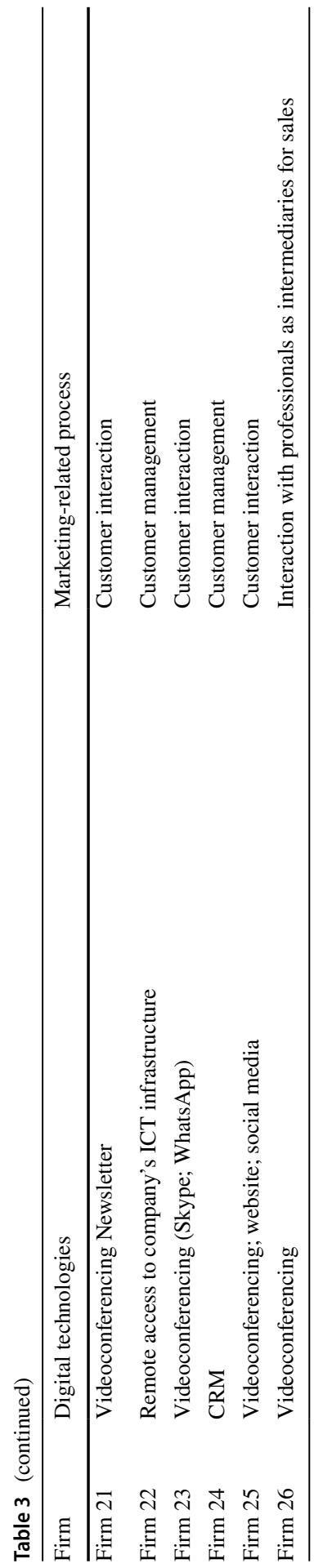


Table 4 Main digital technologies used for marketing purposes during the Italian lockdown. Source: Author's elaboration

\begin{tabular}{lll}
\hline Most used technology & Use & Main marketing purpose \\
\hline Videoconferencing & Interacting with customers & $\begin{array}{c}\text { Managing relationship with customers during the } \\
\text { pandemic }\end{array}$ \\
CRM & $\begin{array}{l}\text { Managing customers } \\
\text { requests or needs effec- } \\
\text { tively } \\
\text { E-commerce }\end{array}$ & $\begin{array}{l}\text { Developing new and customized services } \\
\text { existing customers and } \\
\text { new ones }\end{array}$ \\
& & \\
\hline
\end{tabular}

the single technology, i.e. videoconferencing). Not only firms invested in new technologies that they seldom used before pandemic, but they also increased the intensity of use of the technologies they already have.

For example, the use of videoconferencing technologies to keep in contact with customers and, indirectly, to improve sales performance has been extremely relevant. Firms declared that such technology emerged as a consequence of the physical restrictions imposed by the pandemic. Most of them never used this technology to interact with customers or clients before, but thanks to the pandemic they have been able to manage relationships with existing customers and in the future they will continue to use it, especially for the first preliminary interactions (with new customers). The CEO of Firm 18 maintained:

“...in 25 years I did ten conference calls with clients, now there are three ones per day. Even with employees we used to wait for them to come in for a meeting, now we do the same through Meet, Zoom and it works just as well, it is not $100 \%$ the same thing but you have to get used to it".

CRM emerges as another key technology to manage interactions with customers. During the COVID-19 pandemic, firms used such technology not only to effectively manage customer relationships but also to develop new customized services with positive effects on performance. As the CEO of Firm 8 stated:

"So a few years ago we thought that by putting money on the table for a CRM software we would be okay in reality, we have established a continuous improvement approach and we are still investing in this technology. For example, yesterday we were in a videoconference with 8 people, 4 of which were from our structure, to refine the ticketing management software that is absolutely working, but we always want more".

Finally, there is one more technology very useful to face the crisis and overcome the limitations of the lockdown: e-commerce firms invested in to improve the B2C segment. Through such digital strategy, firms have been able to diversify their offer aiming at reaching different customer segments and markets enlarging the firm strategic vision. The Sales Manager of Firm 13 told us: 
"During the lockdown, we enhanced our website and online shop with new features. We did this by enlarging our warehouse and using an improved ERP integration".

\subsection{Managing customer relationships through digital technologies during the pandemic: evidence from three case studies}

\subsubsection{Videoconferencing: the case of Firm 3}

Firm 3 specializes in designing and building washing machines for trucks, buses and trains and electric vehicles for internal handling and on-road loads. Firm 3 has a turnover of 9 million $€$ with an export of $50 \%$ of the turnover and 36 employees. The company is based in a small town south of Florence (Italy). Operating in both the mechanical and electrical sectors, the company has always been known for its ability to continually improve present products or design new solutions for customer-specific applications.

Although the company has been active during the first lockdown of March and April 2020 (as logistics was one of the industries allowed to operate by Italian law), the company declared that the turnover may have decreased by $35 \%$ in the Italian market and $25 \%$ at the international level. The main problem came from the bus industry: the reduced mobility and the dramatic stop of the touristic industry has decreased the orders by bus service companies. The railway industry is more stable and the company did not expect a decrease in terms of orders. Indeed, the train company asked for new services related to the disinfection of the cars and Firm 3 developed an ozone machine in collaboration with one of its subcontractors. Regardless the pandemic and lockdown, the company did continue in investing in new products, in particular in the development of new small electric vehicles for the transportation of people in historical centers and of goods within the factory.

One of the most important impacts of the pandemic was the implementation of videoconferencing, especially with distant clients. As the CEO of the company told us:

"Working abroad, we travel a lot, including China where we export machines for the railway industry. There we have set up video conferences".

Although the company has just 36 employees and the internal communication is mainly face to face, Firm 3 was forced to react and to heavily use digital technology and often more than one at the same time. As the company declared:

"Advanced technologies are used for contact with customers, and they vary across countries. Example for China we use WeCHAT".

In the past, international fairs and business travels where the most important communication channels with clients. The pandemic and the use of videoconferencing have changed for good relationships with clients. Unexpectedly, for the company: 
"Using this system has allowed us to increase the frequency of meetings and induce everyone to participate: individual interventions increase with video conferences".

This transformation helped the company to increase the quality of service and in particular the process of product personalization that is at the heart of its competitive advantage.

\subsubsection{CRM: Firm 11}

Firm 11 is a Material Science Laboratory and a Software Design House located in the Milan area. The company is specialized in the Italian electronics market for laboratory services, professional education and consultancy, software engineering, and design services on electronic boards and components. Firm 11 has a turnover 30 employees. Thanks to its previous investments in the ERP and in a collaboration platform dedicated to internal communication, the company was able, even before the lockdown, to let its employees to work for from home, especially for the activities that could be managed remotely, such marketing, administration, buying office, design and engineering. Because part of the service provided by Firm 11 is based on the laboratory test of specific materials and electronic components, part of the employees has to go physically to the office. This preexisting (before pandemic) digital infrastructure let the company anticipate the consequences of lockdown and to experiment innovative solutions, especially for professional education. The company was able in one week to test a new set of online courses dedicated to professionals and to market them.

Due to the lockdown, the company had to radically transform the relationship with its clients. The core of this transformation was the CRM (Customer Relationships Management) platform that was already active but was underused. The pandemic pushed the company to communicate with clients in a more precise and intensive way. As the CEO of the company told us:

“... this period has required a much more rigorous use of information than in the past... as far as customer relations are concerned, we have definitely increased the number of newsletters sent and in general we tried to use all our means to contact our clients. We have strengthened our CRM platform, because it has become essential to have quick communications with customers. We have 7000 database contacts and, trivially, having them in the database has given us a major advantage...".

Especially at the beginning of the lockdown, via CRM, the company could communicate promptly that they were open and active and could serve their clients. The company was operating in the industry of electronics that was one of the industries that could operate in the first hard Italian lockdown, but many international clients did not know if the company was open or not. Moreover, the CRM was essential to propose new services to clients like online courses for professional certification. The intensive use of CRM was a revolution in the sales process implemented by the company. Before the pandemic, the sales were based on physical events organized both 
in Italy and internationally, in which representatives of the companies presented the services offered. The event was anticipated by a newsletter message to clients, targeted on the base of the geographical distance of the location of the event. Usually, there were not a formal follow-up of the event, just the company expected some orders from clients. In the pandemic, this sales process clearly was not possible and the company has to use CRM to market clients one-to-one. The platform allowed the firm to increase the level of personalization of the service and the quality of the information exchanged. The company was able to improve the targeting process and to increase the quality of the follow-up thanks to the possibly of tracking all exchange of messages with clients. The results are encouraging as the CEO told us:

"Let's say that clients that were open during the pandemic are very happy with this type of relationship, and those that have closed and that are rebooting now I would say have very much enjoyed this way of interacting with us".

\subsubsection{E-commerce: Firm 19}

Firm 19 is specialized in the production of furniture and is based in Pordenone (close to Venice), within one of the most important Italian furniture districts. The company has a turnover of 8 million euro and 60 employees. Firm 19 was founded 20 years ago and was a traditional second tier subcontractor in the furniture supply chain of global brands like IKEA. In 2014, besides their subcontracting business, the company decided to develop their own brand, Firm 19, and to design and sell pieces of furniture such as tables, chairs, wardrobes, scaffolds, etc. directly to the final consumer. This strategic choice led to the decision to invest in ecommerce and to sell their products both in already existing marketplaces like Amazon and Ebay and directly from the company website. From a marketing point of view, the positioning of the company is primarily based on price and to the velocity of the service: in Italy they are able to deliver the product the next day of the order, internationally the process takes 3 days. Although Firm 19 is increasing the quality of the design, its competitive advantage relies on the opportunity to serve directly the final customer, cutting the costs of the intermediaries that are quite relevant in the furniture business. More importantly, the interaction with the final consumer let the company improve their learning process and increase rapidly its level of service:

"We noticed an increase in users and therefore in searches on our site...we then developed the e-commerce channel for the final consumer...this allows us to think about the development of new types of products and make further optimizations both on the production side and on the management side and go to make improvements, but also on the site itself...".

In a matter of a few years, the B2C part of the business grew exponentially and now accounts for $70 \%$ of the total turnover of the company. Although the company did not quit subcontracting business, ecommerce is the strategic core and where the major part of the investment is concentrated.

That choice has paid off during the pandemic. The company noticed a strong increase in online orders, especially at the international level, by the final customer 
while the subcontracting business almost collapsed. That increase put under pressure production that has to be closed to respect the lockdown. To solve this problem, the company, on the basis of the availability of the product in the inventory, decided to establish a discount system based on the waiting time of delivery. The more the customer was willing to wait the product, the more discount. This helped in segmenting the demand on the base of their needs and expectations and helped the company to not lose orders. Talking about sales in the pandemic, the company said:

"For your wait, we promise you a discount, so it's fine with us because we already have the product sold even before producing it, and on the other hand we have liquidity coming in that allows us to produce products that are asked for less rather than meeting other aspects, so we make a calculation within ourselves of how much we need".

After the lockdown, the company expected a decrease on the online sales due to the fact that stores are open and the customer could find other ways for buying furniture. Quite surprisingly, for the company, this did not happen and sales are still high. This fact has pushed the firm to increase their investment in digital technologies to improve the quality of their relationships with customers. In 2019, before pandemic, the company developed an augmented reality app that could be used to visualize the company product in the room of the client. Unfortunately, that app is not integrated with the ecommerce platform but has just a link to the site. On the basis of the results gathered during the pandemic, the company will develop soon an integration between the app and the commerce platform as well as digital marketing initiatives on social media.

\section{Discussion and conclusions}

The study aimed at investigating, through a multiple-process analysis, how firms used digital technologies to manage markets and customers to face the challenges raised by the COVID-19 pandemic. The first step allowed us identifing what are the most important terms emerged from the word cloud analysis of the interviews collected, suggesting the priorities for firms. Such analysis highlighted the attention for customers during the pandemic, and hence the strategic role of relationships with customers to sustain business and performance. During the lockdown, the customer relationship becomes essential and firms need to improve customer relationship management systems to promote safe interactions (e.g., through online channels) and provide services to sustain business (Donthu \& Gustafsson, 2020). From this point of view, our results are consistent with recent research that has stressed the advantages of servitization and how firms could invest in digital technologies to enhance service provision and new customer solutions by overcoming the physical products (Kohtamäki et al., 2020; Rapaccini et al., 2020).

In the second step of the analysis, based on cross-case comparison, we have highlighted the key role of three types of technologies, namely, videoconferencing, CRM, and e-commerce. Such technologies have been used differently within customer relationship management and they have been related to different strategic 
purposes. If web-based videoconferencing emerged as a key technology within the COVID-19 pandemic to overcome the physical restrictions (He et al., 2021), CRM and e-commerce become strategic technologies able to gain value in the short time (Sen \& Sinha, 2011), even further prior investments implemented before the pandemic. Our findings support the consideration that today CRM strategy is always more considered "a holistic approach to managing customer relationships to create shareholder value" (Payne \& Frow, 2005, p. 168).

The three case studies explored in the third part of our analysis allowed us pointing out the strategic importance of these three communication technologies in managing markets during the COVID-19 crisis. During the lockdown, those technologies played a fundamental role in reconnecting with clients. What was once taken for granted, the dialogue with clients was based on physical meetings, business fairs, social gatherings, etc. had to be rebuilt and reorganized, especially for firms with international clients. Although communications technologies were already used for several years, they played a less relevant role with respect to what emerged through the pandemic, especially in B2B. For example, video conferencing is not a recent technology and it was used for communicating with clients but was used marginally (when physical meetings were not possible) and not considered strategically relevant (Murphy \& Sashi, 2018). The real value in customer relationship management was achieved during the physical meetings. In other words, the COVID-19 crisis highlighted how much the relationships with customers-especially in the B2B markets_-were based on physical interactions (Kang et al., 2020).

The pandemic, and its international spread, increased the uncertainty that companies have to deal with. That uncertainty was also increased by the different regulations and lockdown rules that countries established at the same time. From our qualitative analyses, it emerges the priority of communicating with distant customers that they were open and that the business was running regularly. This was also true for companies that were closed and, nevertheless, they wanted to keep in touch with their clients communicating that they were ready to be back after the lockdown. This may seem trivial but is essential for emotionally reconnecting with clients, especially in the first days of the lockdown.

Beyond this phase of necessity, companies have to adjust their marketing and sales processes to a fully digital world due to the impossibility of physical meetings. That transformation was more complex that it may seem. If in the past, the product was the barycenter of the relationships and the service was a corollary, now servitization becomes a new strategic priority within a servicedominant logic (Lusch \& Vargo, 2006). The quality of service and the capability of the firm in interacting with customers are more important than ever. The pandemic created new challenges that need to be addressed dialogically with clients and asked for new creative solutions as, for example, the discount for the delay in the delivery of the product elaborated by Firm 19. The new digital scenario helped the firm to actively involve new actors in the process of communication and to increase the quality of the service through a better involvement of the client in the design of the product directly from the early phases as we saw in the case of Firm 11. From this perspective, companies seem to use communication technologies for reaching two objectives at the same time: to increase 
the quality of the service offered and implement a customer-centric marketing strategy. This finding seems to confirm the literature of both servitization (Kowalkowski et al., 2017) and customer-centric marketing (Sheth et al., 2000) and brings new insights for the exploration of the combination of these two managerial practices.

Companies used communication technologies also to explore the market and find new customers. This is something more difficult to do, especially for SMEs that are used to find new clients in social gatherings (i.e. fairs). Once considered as a minimum requirement, website, social media and CRM become strategic for presenting company services and products and for searching new clients and exploring new markets. The company learned to find new clients through online initiatives and with a more systematic follow-up, as the case of firm 11 that set up a series of webinars to present their services and then via CRM used the data gathered for specific offerings. That market nurturing through digital contents and initiatives seems to be a relevant change and we expect that it will have a durable impact in the marketing strategy in the future.

In our research, we did not find evidence of an increased use of data-processing technologies (big data and AI applications) in the marketing process as proposed by the literature (Davenport et al., 2020; De Luca et al., 2020; Grandinetti, 2020; Mandelli, 2018). We think that the reason for not finding evidence is twofold. The first one is related to the fact that the pandemic (and lockdown) was an unpredictable event and caught companies totally unprepared. That phenomenon pushed firms to use technologies already at hand or easily and quickly obtainable. Big data and AI are still innovative technologies and relatively unknown to several companies. The second one depends on the complexity of the implementation of those new technological solutions. Big data and AI make data-enabled learning much more powerful than the customer insights produced in the past, but they need specific competences within the firm that take some time to develop (Bettiol et al., 2020b; Hagiu \& Wright, 2020). It is understandable why, in the middle of the pandemic and to solve pressing business issues, companies tried to get out the most from existing technologies. In this sense, web-based technologies are suitable to be used in an easier and faster way because of the higher maturity. This does not mean that those companies will not use big data and AI in the near future. On the contrary, we expect that the complete digitalization of the relationships with customers could lay the ground for a fruitful application of big data and AI to the marketing process, especially for improving the customer experience in the post-COVID era (Barnes, 2020).

We have summarized, in the Fig. 2, the findings emerged from our analyses depicting a conceptual model that stresses the central role of the management of customers during the COVID-19 pandemic and how the firm's digital strategy (especially the we-based technologies based on previous IT investment that require a less complex implementation and adaptation time) may allow firms to improve this customer centricity to reach marketing goals essential to face the pandemic challenges. The conceptual model allowed us to better define the contributions of the research. 


\subsection{Research contributions}

Theoretically, our study contributes to marketing studies exploring the impacts of digitalization on customer relationship management (Kotler et al., 2017) by expanding the discussion in the framework of crisis management. Our original study confirms the importance of exploitation of digital technologies for connecting with customers (Siggelkow \& Terwiesch, 2019) but also that, especially when a crisis emerges, such as during the pandemic, such connectivity involves a plurality of technologies and not all focused on data management and efficiency. Rather, it becomes more relevant customer interaction for brand management and strengthen of customer relationships. From this perspective, we found strong evidence of the impact of web-based technologies (Abed et al., 2015) on the adoption of ecommerce practices. The pandemic has radically digitalized the relationship with costumers. Although not all transactions are closed via digital technologies, the majority of the relationship is now managed online, even in the B2B.

In addition, our study contributes to the literature on the firm's adoption and use of digital technologies. Not only the rate and form of adoption are different in relation to the nature of the firm and of technology (Bettiol et al., 2020a; Büchi et al., 2020; Frank et al., 2019a, b; Ghobakhloo \& Fathi, 2020) but also is unevenly distributed in terms of time and highly sensible to rapid change in the environment. The pandemic and lockdown boosted the adoption and increased the intensity of use of technology. That exogenous stimulus triggered a specific use of technologies, in particular in the relationship with customers, to effectively overcome physical limitations, requesting on the other side quick organizational adjustments. From this perspective, our results confirm recent studies (Papadopoulos et al., 2020) that suggests the importance of organizational ambidexterity in relation to the role played by digital technologies in the time of crisis. Both exploration (finding new solutions) and exploitation (using existing resources) were relevant in the adoption of new technologies. Business continuity and innovation are two facets of the same coin as a way to handle the challenge of the pandemic.

From a managerial point of view, our study suggests that the pandemic pushed firms, and specifically SMEs, to embrace new methods and processes in response and be reactive to the crisis, switching to new operating models focused on customers and supported by business partners. They should, therefore, be technologically ready to avoid business failure during crisis periods that may limit the physical connectivity. The use of the more mature web-based technologies may guarantee them to reach customers and continue the business activities. From the marketing point of view, COVID19 highlighted two main key-points on which firms should focus to manage the crisis. They need to believe in the customer centricity and do the best to satisfy them and take care of them. In this regard, the new digital technologies are strategic for the effectiveness of the relationship mainly through the product and process innovation (Kim, 2020). From this perspective, we could affirm that communication is not just a mean for reaching the client with the appropriate message but is becoming the starting point of the marketing processes itself. 


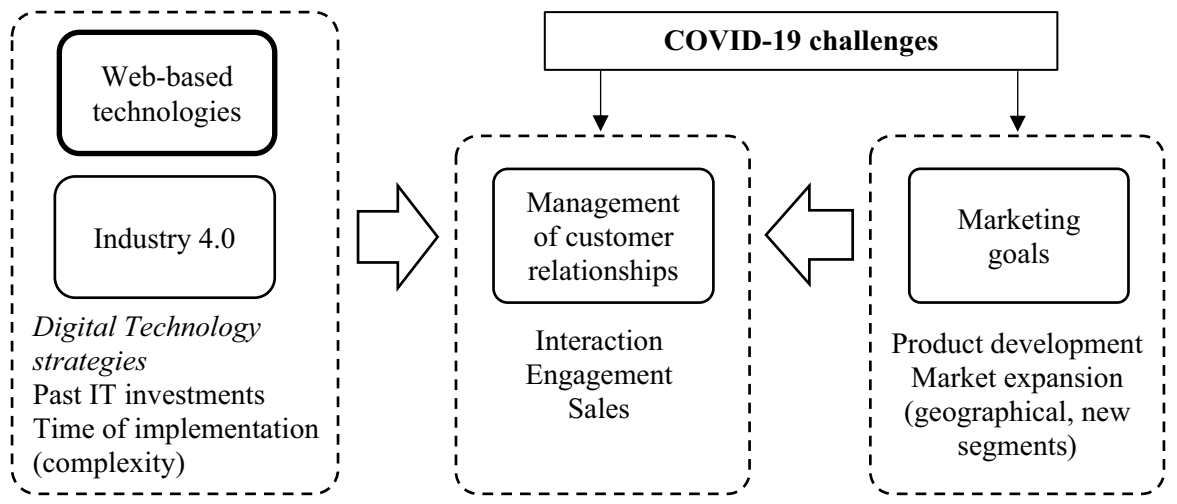

Fig. 2 Digital connectivity in the COVID-19 scenario. Source Author's elaboration

\subsection{Limitations and future research}

We acknowledge that our study has some limitations. We analyzed only a limited number of firms, although through in-depth interviews, and coming from only one country that could influence the results we gathered. Further research should compare not only firms from different countries but also to those with a higher number of firms to verify if what we discovered is a local (Italian) phenomenon or may be generalized. Moreover, we limited the study to the first period of lockdown when firms were shocked by the pandemic and the reaction might be related also to the firm's resilience and entrepreneur crisis management mindset. Hence, an interesting research opportunity could be to expand the time of analysis to further explore those variables that may affect the use of digital technologies for customer purposes. Indeed, future research could further investigated the framework proposed also through additional quantitative empirical studies over time, to further validate it in the post-pandemic context, taking into consideration the role had by the firm's digital capabilities. Nevertheless, we consider our contribution relevant in the debate on the implications of COVID-19 on marketing strategies.

Acknowledgements The authors thank the participants at the SIM Affiliate Workshop "Covid-19 and Marketing Research in Italy" for their valuable comments and suggestions.

Funding Open access funding provided by Università degli Studi di Padova within the CRUI-CARE Agreement. This research has been funded by University of Padova and Ca' Foscari University with the financial support of Società Banca IFIS S.p.A.

\section{Declarations}

Conflicts of interest All the authors declare that they have no conflict of interest.

Open Access This article is licensed under a Creative Commons Attribution 4.0 International License, which permits use, sharing, adaptation, distribution and reproduction in any medium or format, as long as you give appropriate credit to the original author(s) and the source, provide a link to the Creative Commons licence, and indicate if changes were made. The images or other third party material in this article are included in the article's Creative Commons licence, unless indicated otherwise in a credit line to the 
material. If material is not included in the article's Creative Commons licence and your intended use is not permitted by statutory regulation or exceeds the permitted use, you will need to obtain permission directly from the copyright holder. To view a copy of this licence, visit http://creativecommons.org/licen ses/by/4.0/.

\section{References}

Abed, S. S., Dwivedi, Y. K., \& Williams, M. D. (2015). Social media as a bridge to e-commerce adoption in SMEs: a systematic literature review. Marketing Review, 15(1), 39-57. https://doi.org/10.1362/ $146934715 \times 14267608178686$

Acker, O., Gröne, F., Akkad, F., Pötscher, F., \& Yazbek, R. (2011). Social CRM: How companies can link into the social web of consumers. Journal of Direct, Data and Digital Marketing Practice, 13(1), 3-10. https://doi.org/10.1057/dddmp.2011.17

Alcácer, V., \& Cruz-Machado, V. (2019). Scanning the Industry 4.0: A literature review on technologies for manufacturing systems. Engineering Science and Technology, an International Journal. https:// doi.org/10.1016/j.jestch.2019.01.006

Armstrong, A., \& Hagel, J. (1996). The real value of on-line communities. Harvard Business Review, 74(3), 134-141. https://doi.org/10.1016/S0099-1333(97)90159-2

Barnes, S. J. (2020). Information management research and practice in the post-COVID-19 world. International Journal of Information Management. https://doi.org/10.1016/j.ijinfomgt.2020.102175

Bettiol, M., Capestro, M., De Marchi, V., Di Maria, E., \& Sedita, S. R. (2020a). Industrial districts and the fourth industrial revolution. Competitiveness Review. https://doi.org/10.1108/CR-12-2019-0155

Bettiol, M., Capestro, M., Di Maria, E., \& Micelli, S. (2020b). Knowledge and digital strategies in manufacturing firms: the experience of top performers. In M. Bettiol, E. Di Maria, \& S. Micelli (Eds.), Knowledge management and Industry 4.0. New paradigms for value creation (pp. 85-111). Cham: Springer.

Brill, T. M., Munoz, L., \& Miller, R. J. (2019). Siri Alexa, and other digital assistants: a study of customer satisfaction with artificial intelligence applications. Journal of Marketing Management. https://doi.org/10.1080/0267257X.2019.1687571

Büchi, G., Cugno, M., \& Castagnoli, R. (2020). Smart factory performance and Industry 4.0. Technological Forecasting and Social Change, 150, 119790. https://doi.org/10.1016/j.techfore.2019.119790

Burd, M. B. (2019). Build and improve business processes for evaluation consulting. In: N. MartínezRubin, A. A. Germuth, \& M. L. Feldmann (Eds.), Independent evaluation consulting: approaches and practices from a growing field New directions for evaluation (pp. 69-80). Wiley Periodicals Inc.

Cankurtaran, P., \& Beverland, M. (2020). Using design thinking to respond to crises: B2B lessons from the 2020 COVID-19 pandemic. Industrial Marketing Management, 88, 255-260. https://doi.org/10. 1016/j.indmarman.2020.05.030

Chaffey, D., Edmundson-Bird, D., \& Hemphill, T. (2019). Digital business and eE-commerce management. Pearson.

Chang, W., Park, J. E., \& Chaiy, S. (2010). How does CRM technology transform into organizational performance? A mediating role of marketing capability. Journal of Business Research, 63(8), 849-855. https://doi.org/10.1016/j.jbusres.2009.07.003

Chesbrough, H. (2020). To recover faster from Covid-19, open up: Managerial implications from an open innovation perspective. Industrial Marketing Management, 88, 410-413. https://doi.org/10.1016/j. indmarman.2020.04.010

Culot, G., Orzes, G., Sartor, M., \& Nassimbeni, G. (2020). The future of manufacturing: a Delphi-based scenario analysis on Industry 4.0. Technological Forecasting and Social Change. https://doi.org/10. 1016/j.techfore.2020.120092

Davenport, T., Guha, A., Grewal, D., \& Bressgott, T. (2020). How artificial intelligence will change the future of marketing. Journal of the Academy of Marketing Science, 48(1), 24-42. https://doi.org/10. 1007/s11747-019-00696-0

De Luca, L. M., Herhausen, D., Troilo, G., \& Rossi, A. (2020). How and when do big data investments pay off? The role of marketing affordances and service innovation. Journal of the Academy of Marketing Science. https://doi.org/10.1007/s11747-020-00739-x 
Depaolo, C. A., \& Wilkinson, K. (2014). Get your head into the clouds: Using word clouds for analyzing qualitative assessment data. TechTrends, 58, 38-44. https://doi.org/10.1007/s11528-014-0750-9

Drew, S. (2003). Strategic uses of e-commerce by SMEs in the east of England. European Management Journal, 21(1), 79-88. https://doi.org/10.1016/S0263-2373(02)00148-2

Di Roma, A. (2017). Footwear design. The paradox of "tailored shoe" in the contemporary digital manufacturing systems. Design Journal. https://doi.org/10.1080/14606925.2017.1352780

Donthu, N., \& Gustafsson, A. (2020). Effects of COVID-19 on business and research. Journal of Business Research, 117, 284-289. https://doi.org/10.1016/j.jbusres.2020.06.008

Eggers, F. (2020). Masters of disasters? Challenges and opportunities for SMEs in times of crisis. Journal of Busienss Research., 116, 199-208. https://doi.org/10.1016/j.jbusres.2020.05.025

Erevelles, S., Fukawa, N., \& Swayne, L. (2016). Big Data consumer analytics and the transformation of marketing. Journal of Business Research, 69(2), 897-904. https://doi.org/10.1016/j.jbusres. 2015.07.001

Evans, P., \& Wurster, P. (2000). Blown to bits: How the new economics of information transform the strategy. Harvard Business School Press.

Frank, A. G., Mendes, G. H. S., Ayala, N. F., \& Ghezzi, A. (2019a). Servitization and Industry 4.0 convergence in the digital transformation of product firms: A business model innovation perspective. Technological Forecasting and Social Change, 141, 341-351. https://doi.org/10.1016/j. techfore.2019.01.014

Frank, A. G., Dalenogare, L. S., \& Ayala, N. F. (2019b). Industry 4.0 technologies: Implementation patterns in manufacturing companies. International Journal of Production Economics, 210, 15-26. https://doi.org/10.1016/j.ijpe.2019.01.004

Ghobakhloo, M., \& Fathi, M. (2020). Corporate survival in Industry 4.0 era: The enabling role of lean-digitized manufacturing. Journal of Manufacturing Technology Management, 31(1), 1-30. https://doi.org/10.1108/JMTM-11-2018-0417

Grandinetti, R. (2020). How artificial intelligence can change the core of marketing theory. Banks and Bank Systems. https://doi.org/10.21511/im.16(2).2020.08

Hagiu, A., \& Wright, J. (2020). When data creates competitive advantage ... and when it doesn't. Harvard Business Review, 98, 94-101.

Hartmann, N. N., \& Lussier, B. (2020). Managing the sales force through the unexpected exogenous COVID-19 crisis. Industrial Marketing Management. https://doi.org/10.1016/j.indmarman.2020. 05.005

He, W., Zhang, Z., \& Li, W. (2021). Information technology solutions, challenges, and suggestions for tackling the COVID-19 pandemic. International Journal of Information Management. https:// doi.org/10.1016/j.ijinfomgt.2020.102287

Hendricks, K. B., Singhal, V. R., \& Stratman, J. K. (2007). The impact of enterprise systems on corporate performance: A study of ERP, SCM, and CRM system implementations. Journal of Operation Management, 25(1), 65-82. https://doi.org/10.1016/j.jom.2006.02

Hoekstra, J. C., \& Leeflang, P. S. H. (2020). Marketing in the era of COVID-19. Italian Journal of Marketing, 2020, 249-260. https://doi.org/10.1007/s43039-020-00016-3

Hofmann, E., Sternberg, H., Chen, H., Pflaum, A., \& Prockl, G. (2019). Supply chain management and industry 4.0: Conducting research in the digital age. International Journal of Physical Distribution \& Logistics Management, 49(10), 945-955. https://doi.org/10.1108/IJPDLM-11-2019-399

Iansiti, M., \& Lakhani, K. R. (2014). Digital ubiquity: How connections, sensors, and data are revolutionizing business. Harvard Business Review. https://doi.org/10.1017/CBO9781107415324.004

Kang, J., Diao, Z., \& Zanini, M. T. (2020). Business-to-business marketing responses to COVID-19 crisis: A business process perspective. Marketing Intelligence and Planning. https://doi.org/10. 1108/MIP-05-2020-0217

Kim, R. Y. (2020). The impact of COVID-19 on consumers: Preparing for digital sales. IEEE Engineering Management Review, 48(3), 212-218. https://doi.org/10.1109/EMR.2020.2990115

Kohtamäki, M., Parida, V., Patel, P. C., \& Gebauer, H. (2020). The relationship between digitalization and servitization: The role of servitization in capturing the financial potential of digitalization. Technological Forecasting and Social Change. https://doi.org/10.1016/j.techfore.2019.119804

Kotler, P., Harmawan, K., \& Iwan, S. (2017). Marketing 4.0. Moving fron traditional to digital. Wiley.

Kowalkowski, C., Gebauer, H., Kamp, B., \& Parry, G. (2017). Servitization and deservitization: Overview, concepts, and definitions. Industrial Marketing Management, 60, 4-10. https://doi.org/10. 1016/j.indmarman.2016.12.007 
Kozinets, R. V. (1999). E-tribalized marketing?: The strategic implications of virtual communities of consumption. European Management Journal, 17(3), 252-264. https://doi.org/10.1016/S02632373(99)00004-3

Kozinets, R. V. (2002). The field behind the screen: Using netnography for marketing research in online communities. Journal of Marketing Research, 39(1), 61-72. https://doi.org/10.1509/jmkr. 39.1.61.18935

Liao, Y., Deschamps, F., de Loures, E., \& F. R., \& Ramos, L. F. P. . (2017). Past, present and future of Industry 4.0-a systematic literature review and research agenda proposal. International Journal of Production Research, 55(12), 3609-3629. https://doi.org/10.1080/00207543.2017.1308576

Lusch, R. F., \& Vargo, S. L. (2006). The service-dominant logic of marketing: Reactions, reflections, and refinements. Marketing Theory, 6(3), 281-288. https://doi.org/10.1177/1470593106066781

Mandelli, A. (2018). Intelligenza artificiale e marketing. Agenti invisibili, esperienza, valore e business. Egea.

Marchi, G., Giachetti, C., \& De Gennaro, P. (2011). Extending lead-user theory to online brand communities: The case of the community Ducati. Technovation, 31(8), 350-361. https://doi.org/10.1016/j. technovation.2011.04.005

Marston, S., Li, Z., Bandyopadhyay, S., Zhang, J., \& Ghalsasi, A. (2011). Cloud computing-the business perspective. Decision Support System, 51, 176-189. https://doi.org/10.1016/j.dss.2010.12.006

Micelli, S. (2017). Le tre rivoluzioni del management digitale. Sinergie, 35(103), 13-22. https://doi.org/ $10.7433 / \mathrm{s} 103.2017 .01$

Murphy, M., \& Sashi, C. M. (2018). Communication, interactivity, and satisfaction in B2B relationships. Industrial Marketing Management, 68, 1-12. https://doi.org/10.1016/j.indmarman.2017.08.020

Nambisan, S., \& Nambisan, P. (2008). How to profit from a better "virtual customer environment." MIT Sloan Management Review, 49(3), 53-61. https://doi.org/10.2752/175470811X13071166525216

Nenonen, S., \& Storbacka, K. (2020). Don't adapt, shape! Use the crisis to shape your minimum viable system - And the wider market. Industrial Marketing Management, 88, 265-271. https://doi.org/10. 1016/j.indmarman.2020.05.022

Österle, B., Kuhn, M. M., \& Henseler, J. (2018). Brand worlds: Introducing experiential marketing to B2B branding. Industrial Marketing Management, 72, 71-98. https://doi.org/10.1016/j.indmarman. 2018.04.015

Papadopoulos, T., Baltas, K. N., \& Balta, M. E. (2020). The use of digital technologies by small and medium enterprises during COVID-19: Implications for theory and practice. International Journal of Information Management. https://doi.org/10.1016/j.ijinfomgt.2020.102192

Park, C.-H., \& Kim, Y.-G. (2003). A framework of dynamic CRM: Linking marketing with information strategy. Business Process Management Journal, 9(5), 652-671. https://doi.org/10.1108/14637 150310496749

Payne, A., \& Frow, P. (2005). A strategic framework for customer relationship management. Journal of Marketing, 69(October), 167-176. https://doi.org/10.1509/jmkg.2005.69.4.167

Peppers, D., Rogers, M., \& Dorf, B. (1999). Is your company ready for one-to-one marketing? Harvard Business Review, 77(1), 151-160.

Porter, M. E., \& Heppelmann, J. E. (2014). How smart, connected products are transforming competition. Harvard Business Review, 92(11), 64-88.

Rapaccini, M., Saccani, N., Kowalkowski, C., Paiola, M., \& Adrodegari, F. (2020). Navigating disruptive crises through service-led growth: The impact of COVID-19 on Italian manufacturing firms. Industrial Marketing Management, 88, 225-237. https://doi.org/10.1016/j.indmarman.2020.05.017

Robert, M., Giuliani, P., \& Gurau, C. (2020). Implementing industry 4.0 real-time performance management systems: The case of Schneider Electric. Production Planning and Control. https://doi.org/10. 1080/09537287.2020.1810761

Sauter, R., Bode, M., \& Kittelberger, D. (2015). How industry 4.0 is changing how we manage value creation. Horvàth and Partners, Management Consultants, 1, 3-11.

Sawhney, M., Verona, G., \& Prandelli, E. (2005). Collaborating to create: The internet as a platform for customer engagement in product innovation. Journal of Interactive Marketing, 19(4), 4-34. https:// doi.org/10.1002/dir.20046

Schau, H. J., Muñiz, A. M., \& Arnould, E. J. (2009). How brand community practices create value. Journal of Marketing, 73(5), 30-51. https://doi.org/10.1509/jmkg.73.5.30

Sen, A., \& Sinha, A. P. (2011). IT alignment strategies forcustomer relationship management. Decision Support Systems, 51(3), 609-619. https://doi.org/10.1016/j.dss.2010.12.014 
Sharma, A., \& Sheth, J. N. (2004). Web-based marketing: The coming revolution in marketing thought and strategy. Journal of Business Research, 57(7), 696-702. https://doi.org/10.1016/S01482963(02)00350-8

Sheth, J. (2020). Business of business is more than business: Managing during the Covid crisis. Industrial Marketing Management, 88, 261-264. https://doi.org/10.1016/j.indmarman.2020.05.028

Sheth, J. N., Sisodia, R. S., \& Sharma, A. (2000). The antecedents and consequences of customer-centric marketing. Journal of the Academy of Marketing Science, 28, 55-66. https://doi.org/10.1177/00920 70300281006

Siggelkow, N. (2007). Persuasion with case studies. Academy of Management Journal, 50(1), $20-24$. https://doi.org/10.5465/amj.2007.24160882

Siggelkow, N., \& Terwiesch, C. (2019). Connected strategy: Building continuous customer relationships for competitive advantage. Harvard Business School Press.

Sin, L. Y. M., Tse, A. C. B., \& Yim, F. H. K. (2005). CRM: Conceptualization and scale development. European Journal of Marketing, 39(11/12), 1264-1290. https://doi.org/10.1108/030905605106232 53

Soto-Acosta, P. (2020). COVID-19 pandemic: Shifting digital transformation to a high-speed gear. Information Systems Management, 37(4), 260-266. https://doi.org/10.1080/10580530.2020.1814461

Tao, F., Qi, Q., Liu, A., \& Kusiak, A. (2018). Data-driven smart manufacturing. Journal of Manufacturing Systems, 48, 157-169. https://doi.org/10.1016/j.jmsy.2018.01.006

Verma, S., \& Gustafsson, A. (2020). Investigating the emerging COVID-19 research trends in the field of business and management: A bibliometric analysis approach. Journal of Business Research, 118, 253-261. https://doi.org/10.1016/j.jbusres.2020.06.057

Wang, Y., Hong, A., Li, X., \& Gao, J. (2020). Marketing Innovations during a global crisis: A study of china firms' response to COVID-19. Journal of Business Research, 116(1), 214-220. https://doi.org/ 10.1016/j.jbusres.2020.05.029

Wells, J. D., Fuerst, W. L., \& Choobineh, J. (1999). Managing information technology (IT) for one-toone customer interaction. Information \& Management, 35, 53-62. https://doi.org/10.1016/S03787206(98)00076-7

Wu, J., Wu, Z., \& Si, S. (2016). The influences of internet-based collaboration and intimate interactions in buyer-supplier relationship on product innovation. Journal of Business Research, 69(9), 37803787. https://doi.org/10.1016/j.jbusres.2015.12.070

Yin, R. (2004). The case study anthology. Sage.

Yin, S., Zhang, N., \& Dong, H. (2020). Preventing COVID-19 from the perspective of industrial information integration: Evaluation and continuous improvement of information networks for sustainable epidemic prevention. Journal of Industrial Information Integration, 19. https://doi.org/10.1016/j.jii. 2020.100157

Zafari, K., Biggemann, S., \& Garry, T. (2020). Mindful management of relationships during periods of crises: A model of trust, doubt and relational adjustments. Industrial Marketing Management, 88, 278-286. https://doi.org/10.1016/j.indmarman.2020.05.028

Zikmund, W. G. (2013). Business research methods (9th ed.). South-Western.

Publisher's Note Springer Nature remains neutral with regard to jurisdictional claims in published maps and institutional affiliations. 